\title{
Maternal Acculturation and Weight Status Among Young Children of Asian and Hispanic Immigrant Mothers
}

\author{
RaeHyuck Lee ${ }^{1}$
}

Published online: 13 August 2015

(C) Springer International Publishing 2015

\begin{abstract}
Using a nationally representative sample from the Early Childhood Longitudinal Study-Birth Cohort (ECLS-B) and defining maternal acculturation as three patterns of language use, this study examined the influence of maternal acculturation on child weight status at kindergarten entry, separately for children of Asian and Hispanic immigrant mothers. Overall, this study found beneficial associations between maternal acculturation and children's weight status in both Asian and Hispanic groups. Children of bilingual and English-dominant Asian mothers had lower body mass index (BMI) $z$-scores than those of home-language Asian mothers. Maternal acculturation was also associated with a reduced risk of being obese among children of Asian mothers. In addition, children of bilingual Hispanic mothers also had lower BMI $z$-scores than those of home-language Hispanic mothers. The findings of this study suggest that programs to promote the healthy development of young children in immigrant families may need to be tailored to different ethnic groups and levels of maternal acculturation.
\end{abstract}

Keywords Maternal acculturation $\cdot$ Child weight development $\cdot$ Kindergarteners $\cdot$ Asian immigrants $\cdot$ Hispanic immigrants $\cdot$ ECLS-B

\section{Introduction}

One fourth of children under age 6 in the USA are those in immigrant families, and the majority of these young children

RaeHyuck Lee

raehyucklee@gmail.com

1 Columbia University School of Social Work, 1255 Amsterdam Avenue, New York, NY 10027, USA are Asian and Hispanic (Hernandez 2004; Shields and Behrman 2004). In concert with this demographic change, there has been a growing concern about being overweight and obese among young children of immigrant families (Au et al. 2009; California Department of Health Care Services n.d.; Ogden et al. 2010). The prevalence of being overweight and obese among young Hispanic children has been well documented (Ogden et al. 2010; Whitaker and Orzol 2006). In the 2007-2008 National Health and Nutrition Examination Survey, $43 \%$ of Hispanic children were overweight and $25 \%$ were obese, compared with $35 \%$ and $19 \%$ of their non-Hispanic White counterparts, respectively (Ogden et al. 2010). Although Asian children show lower prevalence of being overweight and obese compared with their Hispanic peers, a study using data from the 2003 National Survey of Children's Health found that $32 \%$ of Asian American children were overweight and $15 \%$ were obese (Singh et al. 2009). Given that children who were overweight or obese before kindergarten entry were substantially more likely to be overweight or obese at later school years compared with those who were not (Nader et al. 2006), it is critical to understand which factors affect the early development of being overweight and obese among young children of Asian and Hispanic immigrants.

Prior research has consistently found that recent immigrants are in better health than their counterpart natives, but this health advantage declines with greater acculturation into American society (Chen 2009; Cho et al. 2004). However, it is not clear whether this pattern holds when it comes to the association between parental acculturation and young children's weight development (Van Hook and Baker 2010; Van Hook and Balistreri 2007). Research on this topic has been mixed, with studies suggesting negative, positive, or no associations between parental acculturation and children's weight as well as behaviors related to being overweight and obese, 
such as an unhealthy diet and sedentary activity (Ariza et al. 2004; Chen and Kennedy 2005; Fuller et al. 2009; Sussner et al. 2008). Acculturation involves a process of adopting values and attitudes from the destination culture (Berry 2005). Therefore, parental acculturation may change immigrant parents' preferences and behaviors related to dietary habits and physical activities and increase opportunities to obtain health knowledge, all of which would result in preventing unhealthy weight gain among their young children (Guendelman et al. 2010). However, surprisingly little is known about how parental acculturation is associated with young children's weight development.

Further, given that childhood obesity has been situated in a coherent global context (Waters et al. 2010), understanding this growing concern for children of immigrants is necessary in an effort to provide global implications. Therefore, using a nationally representative birth cohort from the Early Childhood Longitudinal Study-Birth Cohort (ECLS-B), this study examines how maternal acculturation is associated with child weight status (as measured by body mass index (BMI) $z$ scores and being overweight or obese) at kindergarten entry among children of Asian and Hispanic immigrant mothers. As recommended by recent research (Hernandez et al. 2013), due to ethnic heterogeneity in maternal acculturation and child development, this study conducts separate analyses for children of Asian and Hispanic immigrant mothers.

\section{Background}

\section{Conceptual Frameworks}

An integrated model of health promotion posits child healthpromoting behaviors as a function of both individual and environmental factors, and therefore within this model, parents are considered as an important interpersonal factor that directly affects children's health-promoting behaviors (Wilson and Evans 2003). Similarly, focusing on the role of immigrant parents in the early development of preschool-age children, a multi-disciplinary model explains that parental acculturation is an important factor for children's early development (Chase-Lansdale et al. 2007). This study is framed within these conceptual frameworks, and therefore this study expects that maternal acculturation would play an important role in predicting early childhood weight development.

\section{Prior Research on Parental Acculturation and Child Weight Development}

Few studies have to date examined the association between parental acculturation and child weight status among young children in immigrant families. Using a sample of 91 children whose mothers were predominantly low-income Latino immigrants in Boston and Springfield metropolitan areas, Sussner et al. (2008) investigated the influence of maternal acculturation on child BMI scores. Measuring maternal acculturation as mother's nativity, years of US residence, and language use, they found that children whose mothers exclusively used their native language at home had higher BMI $z$-scores at age 24 months compared with those whose mothers nonexclusively used their native language. However, the significant influence vanished at age 36 months, and other acculturation measures were not associated with children's BMI at both 24 and 36 months. In another study, using a sample of two hundred fifty 5 - to 6-year-old children of predominantly Mexican immigrant families living in Chicago, Ariza et al. (2004) found that there was no significant association between child overweight status and maternal acculturation measured using a scale describing language, social relations, and media use. Using data from the ECLS-B, another study reported no association between maternal acculturation (i.e., language use at home, nativity, and years residing in the USA) and Latino children's BMI at 24 months of age (Fuller et al. 2009). Evidence from a study using a sample of school-age children is also relevant. Using a small sample of sixty-eight 8- to 10year-old Chinese American children living in California, Chen and Kennedy (2005) found that children whose mothers had low acculturation scores (as measured on the Suinn-Lew Asian Self-Identity Acculturation scale) were more likely to be overweight compared with those whose mothers had high acculturation scores.

Taken together, prior research using small samples of Hispanic or Mexican immigrants shows that parental acculturation was associated with lower BMI scores or not associated with BMI scores in younger children or kindergarteners. In contrast, nothing is known about kindergarten-age children of Asian immigrants, although relevant evidence from a study using a sample of school-age Asian children suggests that maternal acculturation is associated with lower BMI scores. In sum, we know little about how maternal acculturation is associated with child weight status among a nationally representative sample of children of Asian or Hispanic immigrants, and thus more research is necessary for a deeper understanding.

\section{The Present Study}

This study aims to examine the associations between maternal acculturation and child weight status at kindergarten entry, separately for children of Asian and Hispanic immigrant mothers. Although almost no evidence is available for maternal acculturation and its influence on kindergarten-age children's weight development, based on limited empirical evidence together with conceptual frameworks discussed above, this study expects that maternal acculturation may be associated with lower BMI scores as well as lower probabilities of 
being overweight and obese among children of both Asian and Hispanic groups.

In doing so, this study extends the literature in several respects. First, this study uses a nationally representative birth cohort of children of foreign-born Asian and Hispanic mothers from the ECLS-B. Second, this study examines the influences of maternal acculturation on probabilities of being overweight and obese as well as on BMI scores, unlike prior studies mainly focusing on BMI scores. Finally, this study considers maternal acculturation as diverse patterns of being American or adjusting to American society among recent Asian and Hispanic immigrants (as measured by three patterns of maternal language use) in contrast to much prior research defining acculturation as a linear process from not acculturated to acculturated.

\section{Method}

\section{Data and Sample}

This study used data from the ECLS-B. The ECLS-B is a nationally representative sample of about 10,700 children born in the USA in 2001 who were assessed at 9 months, 2 years, 4 years, and 5 or 6 years (Snow et al. 2009). About $75 \%$ of children who entered kindergarten in 2006 were assessed at the 2006 kindergarten survey and the rest at $25 \%$ who entered kindergarten in 2007 were assessed at the 2007 kindergarten survey. Therefore, this study combined data of the both 2006 and 2007 surveys to measure weight outcomes at kindergarten entry. Following NCES guidelines for the use of restricted data, all sample sizes reported in this study were rounded to the nearest 50 (Snow et al. 2009).

Due to financial constraints (Snow et al. 2009), about 7000 children and their parents were assessed at the kindergarten survey. Of these, this study selected about 1500 children whose mothers were born in Asian and Latin American countries. Therefore, the final sample of this study included about 850 children of foreign-born Asian mothers (about $40 \%$ from China and the rest from Japan, Philippine, India, Korea, Vietnam, and other Asia or Pacific Island) and about 650 children of foreign-born Hispanic mothers (about $70 \%$ from Mexico and the rest from Puerto Rico, Cuba, and other Central or South America).

\section{Measures}

\section{Maternal Acculturation}

Acculturation among recent immigrants is not a linear process from not acculturated to acculturated (Berry 2005; Lara et al. 2005; Salant and Lauderdale 2003). Therefore, to better measure diverse acculturation patterns among recent Asian and Hispanic immigrant mothers, this study used two variablesmothers' primary language at home and English proficiency, which were collected at the 9-month survey. Maternal primary language at home was measured as a binary variable with a value of 1 if English is the primary language at home and 0 otherwise. Maternal English proficiency was measured as the total score (ranging from 0 to 12) of four items that asked how well the mother speaks, reads, writes, and understands English, with a 4-point Likert scale $(0=$ "not well at all" to $3=$ "very well") at the 9-month survey. Using these two variables, this study created three acculturation groups of Asian and Hispanic immigrant mothers: (1) mothers who primarily used English at home (hereafter, English-dominant mothers); (2) mothers who primarily used their home language at home but also had high English proficiency (as measured by speaking, reading, writing, and understanding English very well or pretty well; hereafter, bilingual mothers); and (3) mothers who primarily used their home language at home and had low English proficiency (as measures by speaking, reading, writing, or understanding English not very well or not well at all; hereafter, homelanguage mothers). In addition, this study included mothers' length of stay in the USA in all analyses since a longer stay in the host country is also associated to becoming more integrated into the new culture (Lara et al. 2005; Salant and Lauderdale 2003). Mothers' length of residency in the USA was measured by subtracting their current age from their age at arrival in the USA collected at the 2-year survey.

\section{Children's Weight Outcomes}

This study used BMI $z$-scores as an outcome measure by standardizing BMI scores provided in the kindergarten survey of the ECLS-B based on children's gender and age in months (Centers for Disease Control and Prevention n.d.). Using the age- and gender-specific growth charts for the USA, this study created another categorical outcome measure identifying overweight and obese children: (1) children with BMI below the 85th percentile as a normal weight category; (2) children with BMI between the 85th and 95th percentiles as an overweight category; and (3) children with BMI at or above the 95th percentile as an obese category.

\section{Control Variables}

This study included a wide set of control variables, all of which were chosen based on their theoretical and empirical relevance for maternal acculturation and child development (Chase-Lansdale et al. 2007; Fuller et al. 2009; Wilson and Evans 2003). Child characteristics included gender, multiple birth, low birth weight, and age in months at the 9-month survey. Family background characteristics included mothers' age, marital status, and education, family income, and the number of siblings at the 9-month survey. Also included was mothers' BMI before pregnancy. This study also controlled for two variables related to family process at the preschool 
survey: maternal employment and child care arrangements. In addition, this study included seven parenting behavior variables collected at the preschool survey: mothers' use of spanking in the past week, family sleeping routine, the frequency of eating dinner together per week, the frequency of consumption of healthy eating items in the past week - milk, vegetable, and fruit, the frequency of consumption of unhealthy eating items in the past week - soda, fast food, salty snack, and sweet snack, watching TV per weekday, and the frequency of outdoor activities in the past month.

\section{Analysis Plans}

To examine the association between maternal acculturation and child weight development, this study specified four models relying on Ordinary Least Squares (OLS) regressions for BMI $z$ scores or multi-nominal logistic regressions for overweight and obese status. Children's weight outcomes were predicted by the following four models that increasingly included covariates, separately for children of Asian and Hispanic immigrant mothers. Model 1, which only included the measure of acculturation and child characteristics, estimated basic variations in children's weight outcomes across maternal acculturation groups; two binary indicators for children who entered kindergarten in 2006 vs. 2007 and for mothers' country of origin were also included in model 1 . Model 2 was the same as model 1 but added mothers' length of US residency to see if including the variable makes changes in the coefficients of maternal acculturation groups. Model 3 was the same as model 2 but added mothers' BMI scores before pregnancy to examine whether variations across maternal acculturation groups are explained by mothers' weight status before pregnancy. Finally, model 4, the final model, was the same as model 3 but added variables for family characteristics at the 9-month survey and for factors related to family processmaternal employment, child care arrangements, and parenting behavior at the preschool survey; a binary indicator for the presence of fathers at home at the 9-month survey was also included in model 4. In all analyses, this study employed sampling weights provided in the ECLS-B to take into account the complex sampling structure of the ECLS-B (Snow et al. 2009). To address missing data on some covariates, multiple imputations were employed with ten imputed datasets, which resulted in $99.9 \%$ of the recovery rate of missing data (Rubin 1987).

\section{Results}

For brevity, three important patterns are described with respect to the results of descriptive analyses presented in Table 1 . First, substantially more Asian mothers used English at home predominantly or along with their home-language compared with Hispanic mothers. Home-language, bilingual, and English-dominant mothers were 27, 46, and $27 \%$, respectively, in the Asian group, and 9, 22, and $68 \%$, respectively, in the Hispanic group. Second, when staying in the USA for longer years, Asian mothers tended to use English mainly, but Hispanic mothers tended to use English as well as their home language. Finally, children of English-dominant Asian mothers tended to have lower BMI scores and were less likely to be obese than those of home-language Asian mothers, but children of both bilingual and Englishdominant Hispanic mothers tended to have lower BMI scores than those of home-language Hispanic mothers.

Table 2 shows the results of the OLS regression models for BMI scores, separately for Asian and Hispanic groups; the full results including all control variables are not present here but available upon request. Overall, in the final model including all control variables, this study found beneficial associations between maternal acculturation and children's BMI scores in both Asian and Hispanic groups. As expected, children of bilingual and English-dominant Asian mothers had lower BMI scores $(b=-0.19, p<0.01$ and $b=-0.28, p<0.001)$ than those of home-language Asian mothers in model 4 (Children of Asian mothers, Table 2). In addition, children of bilingual Hispanic mothers also had lower BMI scores $(b=-0.23, p<0.05)$ than those of home-language Hispanic mothers in model 4 (Children of Hispanic mothers, Table 2).

Table 3 presents the results of the multi-nominal logistic regression models for overweight and obese status of Asian mothers. Overall, beneficial associations between maternal acculturation and probabilities of being overweight and obese were found among children of Asian mothers but not those of Hispanic mothers. Specifically, children of English-dominant Asian mothers tended to be less likely to be overweight compared with children of home-language Asian mothers in model 4; the odd ratio was $0.52(p<0.10)$, which suggests that the probability of being overweight for children of English-dominant Asian mothers tended to be about $48 \%$ less than that for those of home-language Asian mothers. Also, children of Englishdominant Asian mothers were less likely to be obese compared with those of home-language Asian mothers in model 4; the odd ratio was $0.22(p<0.05)$, which indicates that the probability of being obese for children of English-dominant Asian mothers was about $78 \%$ less than that for those of home-language Asian mothers (Obese status, Table 3). The corresponding results for children of Hispanic mothers are not presented here but available upon request; briefly, maternal acculturation was associated with lower odds of being overweight and obesity in models 1 and 2, but such beneficial associations were gone after adding mothers' BMI before pregnancy in model 3.

\section{Discussion and Conclusion}

This study is the first to use a contemporary and nationally representative sample of children to examine the associations 
Table 1 Descriptive statistics for all variables by maternal ethnicity and acculturation

\begin{tabular}{|c|c|c|c|c|c|c|c|c|}
\hline \multirow[t]{2}{*}{ Variable } & \multicolumn{4}{|c|}{ Children of Asian immigrant mothers } & \multicolumn{4}{|c|}{ Children of Hispanic immigrant mothers } \\
\hline & $\begin{array}{l}\text { Total } \\
(n \approx 850)\end{array}$ & $\begin{array}{l}\text { Home language } \\
(n \approx 250)\end{array}$ & $\begin{array}{l}\text { Bilingual } \\
(n \approx 400)\end{array}$ & $\begin{array}{l}\text { English dominant } \\
(n \approx 200)\end{array}$ & $\begin{array}{l}\text { Total } \\
(n \approx 650)\end{array}$ & $\begin{array}{l}\text { Home language } \\
(n \approx 450)\end{array}$ & $\begin{array}{l}\text { Bilingual } \\
(n \approx 150)\end{array}$ & $\begin{array}{l}\text { English dominant } \\
(n \approx 100)\end{array}$ \\
\hline \multicolumn{9}{|l|}{ Maternal acculturation } \\
\hline Home-language mothers & 0.27 & 1.00 & & & 0.68 & 1.00 & & \\
\hline Bilingual mothers & 0.46 & & 1.00 & & 0.22 & & 1.00 & \\
\hline English-dominant mothers & 0.27 & & & 1.00 & 0.09 & & & 1.00 \\
\hline Years of US residency & 12.05 & 8.08 & $10.91 * * *$ & $18.04 * * * \mathrm{c}$ & 11.05 & 8.65 & $15.75^{* * *}$ & $17.78 * * * \mathrm{a}$ \\
\hline \multicolumn{9}{|c|}{ Child weight outcomes at kindergarten } \\
\hline BMI & -0.45 & -0.35 & -0.46 & $-0.54^{*}$ & 0.09 & 0.17 & $-0.14 * *$ & $-0.12^{\dagger}$ \\
\hline Overweight status & 0.12 & 0.14 & 0.13 & 0.08 & 0.20 & 0.22 & 0.15 & 0.16 \\
\hline Obese status & 0.05 & 0.08 & 0.05 & $0.03^{\dagger}$ & 0.19 & 0.20 & 0.14 & 0.15 \\
\hline \multicolumn{9}{|l|}{ Child characteristics } \\
\hline Age in months at 9 months & 10.45 & 10.53 & 10.42 & 10.45 & 10.28 & 10.32 & 10.23 & 10.26 \\
\hline Boys & 0.53 & 0.55 & 0.53 & 0.54 & 0.52 & 0.54 & 0.47 & 0.47 \\
\hline Low birth weight at birth & 0.06 & 0.08 & 0.05 & 0.05 & 0.06 & 0.05 & 0.05 & $0.12^{\dagger}$ \\
\hline \multicolumn{9}{|c|}{ Family background characteristics } \\
\hline Age at birth & 30.45 & 30.99 & 30.45 & $29.74 *$ & 27.05 & 27.44 & 26.65 & $25.81^{\dagger}$ \\
\hline Married at birth & 0.92 & 0.96 & 0.95 & $0.84 * * * \mathrm{c}$ & 0.63 & 0.63 & 0.63 & 0.61 \\
\hline \multicolumn{9}{|l|}{ Maternal education at birth } \\
\hline Less than high school & 0.09 & 0.24 & $0.03 * * *$ & $0.05 * * *$ & 0.56 & 0.67 & $0.31 * * *$ & $0.36^{* * *}$ \\
\hline High school graduate & 0.21 & 0.33 & $0.16^{* * *}$ & $0.16^{* * *}$ & 0.26 & 0.22 & $0.36^{* *}$ & 0.29 \\
\hline Some college or more & 0.70 & 0.42 & $0.81 * * *$ & $0.79 * * *$ & 0.18 & 0.10 & $0.33 * * *$ & $0.35^{* * *}$ \\
\hline \multicolumn{9}{|l|}{ Family income at 9 months } \\
\hline$\$ 0-20,000$ & 0.12 & 0.25 & $0.06^{* * *}$ & $0.09 * * *$ & 0.39 & 0.47 & $0.21 * * *$ & $0.29 *$ \\
\hline$\$ 20,001-35,000$ & 0.18 & 0.28 & $0.15^{* * *}$ & $0.14^{* *}$ & 0.39 & 0.41 & 0.38 & $0.24 *$ \\
\hline$\$ 35,001-50,000$ & 0.34 & 0.34 & 0.34 & 0.33 & 0.18 & 0.11 & $0.36^{* * *}$ & $0.24 * \mathrm{a}$ \\
\hline$\$ 50,000$ or more & 0.36 & 0.12 & $0.44 * * *$ & $0.43^{* * *}$ & 0.04 & 0.01 & $0.05^{\dagger}$ & $0.22 * * * \mathrm{c}$ \\
\hline \multicolumn{9}{|c|}{ Number of siblings at 9 months } \\
\hline None & 0.46 & 0.46 & 0.47 & 0.44 & 0.41 & 0.38 & $0.49^{\dagger}$ & 0.46 \\
\hline 1 & 0.38 & 0.36 & 0.40 & 0.37 & 0.27 & 0.27 & 0.29 & 0.28 \\
\hline 2 or more & 0.16 & 0.18 & 0.13 & 0.19 & 0.32 & 0.35 & $0.23 *$ & 0.26 \\
\hline $\begin{array}{l}\text { Maternal BMI before } \\
\text { pregnancy }\end{array}$ & 21.84 & 21.04 & $22.15^{* *}$ & $22.03 *$ & 24.79 & 24.93 & 24.44 & 24.80 \\
\hline \multicolumn{9}{|c|}{ Maternal employment, child care, and parenting } \\
\hline \multicolumn{9}{|c|}{ Maternal employment at preschool } \\
\hline Not working & 0.41 & 0.52 & $0.36^{* * *}$ & $0.39 *$ & 0.54 & 0.60 & $0.40 * * *$ & 0.48 \\
\hline Part-time & 0.16 & 0.19 & 0.13 & 0.18 & 0.11 & 0.10 & 0.10 & 0.16 \\
\hline Full-time & 0.43 & 0.29 & $0.52 * * *$ & $0.43 *$ & 0.35 & 0.30 & $0.50 * * *$ & 0.36 \\
\hline \multicolumn{9}{|c|}{ Child care arrangements at preschool } \\
\hline Parental care & 0.17 & 0.22 & $0.13 * *$ & 0.16 & 0.32 & 0.40 & $0.16^{* * *}$ & $0.11 * * *$ \\
\hline Relative care & 0.14 & 0.08 & $0.18^{* *}$ & $0.16^{\dagger}$ & 0.14 & 0.12 & 0.19 & 0.16 \\
\hline Non-relative care & 0.04 & 0.03 & 0.04 & 0.05 & 0.06 & 0.07 & 0.03 & 0.05 \\
\hline Other center-based care & 0.58 & 0.52 & $0.62 *$ & 0.58 & 0.23 & 0.17 & $0.37 * * *$ & $0.36^{* *}$ \\
\hline Head start & 0.07 & 0.14 & $0.03 * * *$ & $0.06^{* *}$ & 0.25 & 0.25 & 0.25 & 0.32 \\
\hline \multicolumn{9}{|c|}{ Parenting behaviors at preschool } \\
\hline Use of spanking & 0.22 & 0.21 & 0.22 & 0.24 & 0.23 & 0.22 & 0.24 & 0.32 \\
\hline Having sleeping routines & 0.87 & 0.88 & 0.84 & $0.91 \mathrm{a}$ & 0.77 & 0.74 & 0.79 & $0.89 *$ \\
\hline $\begin{array}{l}\text { Eating dinner together } \\
\text { a week }\end{array}$ & 5.42 & 5.37 & 5.66 & $5.07 \mathrm{~b}$ & 4.43 & 4.49 & 4.25 & 4.49 \\
\hline
\end{tabular}


Table 1 (continued)

\begin{tabular}{|c|c|c|c|c|c|c|c|c|}
\hline \multirow[t]{2}{*}{ Variable } & \multicolumn{4}{|c|}{ Children of Asian immigrant mothers } & \multicolumn{4}{|c|}{ Children of Hispanic immigrant mothers } \\
\hline & $\begin{array}{l}\text { Total } \\
(n \approx 850)\end{array}$ & $\begin{array}{l}\text { Home language } \\
(n \approx 250)\end{array}$ & $\begin{array}{l}\text { Bilingual } \\
(n \approx 400)\end{array}$ & $\begin{array}{l}\text { English dominant } \\
(n \approx 200)\end{array}$ & $\begin{array}{l}\text { Total } \\
(n \approx 650)\end{array}$ & $\begin{array}{l}\text { Home language } \\
(n \approx 450)\end{array}$ & $\begin{array}{l}\text { Bilingual } \\
(n \approx 150)\end{array}$ & $\begin{array}{l}\text { English dominant } \\
(n \approx 100)\end{array}$ \\
\hline Healthy eating habits & 32.75 & 33.84 & 32.06 & 32.60 & 37.47 & 38.73 & $35.37^{\dagger}$ & $33.09 *$ \\
\hline Unhealthy eating habits & 15.05 & 17.14 & $13.61^{* *}$ & 15.00 & 18.19 & 18.86 & 16.81 & $15.18^{\dagger}$ \\
\hline $\begin{array}{l}\text { Watching TV per } \\
\text { weekday }\end{array}$ & 2.06 & 2.06 & 1.95 & 2.12 & 3.29 & 3.47 & 2.81 & 2.97 \\
\hline Outdoor activities & 4.10 & 4.21 & $4.00 *$ & 4.18 & 4.41 & 4.44 & 4.38 & 4.37 \\
\hline
\end{tabular}

Notes. All mean scores were weighted using 9-month (W1R0), 2-year (W2R0), preschool (W31R0), or kindergarten (WK1R0) sampling weights. Sample sizes were rounded to the nearest 50, due to IES reporting rules. Descriptive statistics for the multiple birth variables were not presented due to small cell sizes. Significance tests were conducted to compare means for children of native-language mothers to those for children of bilingual and English-dominant mothers, separately for Asian and Hispanic groups. Additionally, significance tests were conducted to compare means between children of bilingual and English-dominant mothers (marked with lowercase letters): $p<0.10$ (a); $p<0.01$ (b), and $p<0.001$ (c)

$B M I$ body mass index

${ }^{\dagger} p<0.10 ;{ }^{*} p<0.05 ; * * p<0.01 ; * * * p<0.001$

between maternal acculturation and child weight status at kindergarten entry among children of Asian and Hispanic immigrant mothers. Another novel aspect of this study is its measurement of acculturation among recent Asian and Hispanic immigrant mothers. Unlike prior studies, this study defined acculturation not as a linear process but as diverse patterns resulting from maintenance of the origin culture and contact with the new culture (Berry 2005; Lara et al. 2005; Salant and Lauderdale 2003). As expected based on conceptual and empirical evidence, this study found beneficial associations of maternal acculturation with children's weight outcomes at kindergarten entry, in both Asian and Hispanic groups. Compared with children of less acculturated mothers (i.e., home- language ones), children of more acculturated mothers (i.e., English-dominant or bilingual ones) had lower BMI scores in both Asian and Hispanic groups and were less likely to be obese in the Asian group.

As expected, this study found lower BMI scores and lower odds of being obese among children of English-dominant or bilingual Asian mothers compared with those of homelanguage Asian mothers. This finding is consistent with prior research reporting lower BMI scores among Chinese American children of more acculturated mothers (Chen and Kennedy 2005), and further extends prior research by showing that maternal acculturation was associated with a reduced risk of obesity among children of Asian immigrant mothers.

Table 2 Maternal acculturation and BMI at kindergarten entry among children of Asian and Hispanic immigrant mothers

\begin{tabular}{|c|c|c|c|c|}
\hline & $\begin{array}{l}\text { Model } 1 \\
\text { Coefficient (SE) }\end{array}$ & $\begin{array}{l}\text { Model } 2 \\
\text { Coefficient (SE) }\end{array}$ & $\begin{array}{l}\text { Model } 3 \\
\text { Coefficient (SE) }\end{array}$ & $\begin{array}{l}\text { Model } 4 \\
\text { Coefficient (SE) }\end{array}$ \\
\hline \multicolumn{5}{|l|}{ Children of Asian mothers } \\
\hline \multicolumn{5}{|l|}{ Maternal acculturation } \\
\hline Bilingual mothers & $-0.11^{\dagger}(0.06)$ & $-0.11^{\dagger}(0.06)$ & $-0.15 *(0.06)$ & $-0.19 * *(0.07)$ \\
\hline English-dominant mothers & $-0.19 * *(0.07)$ & $-0.20 * *(0.07)$ & $-0.21 * *(0.07)$ & $-0.28 * * *(0.08)$ \\
\hline Maternal years of US residency & & $0.00(0.00)$ & $-0.00(0.00)$ & $0.00(0.00)$ \\
\hline \multicolumn{5}{|l|}{ Children of Hispanic mothers } \\
\hline \multicolumn{5}{|l|}{ Maternal acculturation } \\
\hline Bilingual mothers & $-0.31 * *(0.10)$ & $-0.33 * *(0.11)$ & $-0.27 *(0.10)$ & $-0.23 *(0.12)$ \\
\hline English-dominant mothers & $-0.24^{\dagger}(0.14)$ & $-0.27^{\dagger}(0.16)$ & $-0.19(0.15)$ & $-0.12(0.17)$ \\
\hline Maternal years of US residency & & $0.00(0.01)$ & $-0.00(0.01)$ & $-0.00(0.01)$ \\
\hline
\end{tabular}

Notes. Reference acculturation group was home-language mothers. All regressions were adjusted using the kindergarten sampling weights (WK1R0). Sample sizes were rounded to the nearest 50, due to IES reporting rules; in all models, sample sizes were about 800 for the Asian group and 600 for the Hispanic group. Model 1 only included acculturation groups and child characteristics; model 2 was the same as model 1 but added maternal years of US residency; model 3 was the same as model 2 but added maternal BMI before pregnancy; and model 4 was the same as model 3 but added family background and process variables

$B M I$ body mass index, $S E$ standard error of the coefficient

${ }^{\dagger} p<0.10 ; * p<0.05 ; * * p<0.01 ; * * *<<0.001$ 
Table 3 Maternal acculturation and overweight and obese status at kindergarten entry among children of Asian immigrant mothers

\begin{tabular}{|c|c|c|c|c|}
\hline & $\begin{array}{l}\text { Model } 1 \\
\text { OR }(95 \% \text { CI) }\end{array}$ & $\begin{array}{l}\text { Model } 2 \\
\text { OR }(95 \% \text { CI })\end{array}$ & $\begin{array}{l}\text { Model } 3 \\
\text { OR }(95 \% \mathrm{CI})\end{array}$ & $\begin{array}{l}\text { Model } 4 \\
\text { OR }(95 \% \text { CI })\end{array}$ \\
\hline \multicolumn{5}{|l|}{ Overweight status } \\
\hline \multicolumn{5}{|l|}{ Maternal acculturation } \\
\hline Bilingual mothers & $0.85(0.52-1.39)$ & $0.91(0.55-1.49)$ & $0.81(0.49-1.35)$ & $0.76(0.41-1.39)$ \\
\hline English-dominant mothers & $0.49 *(0.27-0.90)$ & $0.61(0.31-1.20)$ & $0.60(0.31-1.19)$ & $0.52 \dagger(0.23-1.13)$ \\
\hline Maternal years of US residency & & $0.98(0.94-1.01)$ & $0.97 *(0.93-0.99)$ & $0.97(0.93-1.01)$ \\
\hline \multicolumn{5}{|l|}{ Obese status } \\
\hline \multicolumn{5}{|l|}{ Maternal acculturation } \\
\hline Bilingual mothers & $0.61(0.30-1.22)$ & $0.64(0.32-1.30)$ & $0.55(0.26-1.13)$ & $0.52(0.19-1.40)$ \\
\hline English-dominant mothers & $0.33 *(0.13-0.83)$ & $0.42 \dagger(0.15-1.13)$ & $0.36 \dagger(0.13-1.00)$ & $0.22 *(0.06-0.79)$ \\
\hline Maternal years of US residency & & $0.97(0.92-1.02)$ & $0.97(0.92-1.02)$ & $0.98(0.92-1.04)$ \\
\hline
\end{tabular}

Notes. Reference acculturation group was home-language mothers. All multi-nominal regressions, omitting the normal weight category, were adjusted using the kindergarten sampling weights (WK1R0). Sample sizes were rounded to the nearest 50, due to IES reporting rules; sample sizes were about 800 in all models. Model 1 only included acculturation groups and child characteristics; model 2 was the same as model 1 but added maternal years of US residency; model 3 was the same as model 2 but added maternal BMI before pregnancy; and model 4 was the same as model 3 but added family background and process variables

$O R$ odds ratio, $C I$ confidence interval

$\dagger p<0.10 ;{ }^{*} p<0.05$

One possible explanation of this finding is that Asian immigrant mothers who speak English well may have better ability to recognize the seriousness of their children's overweight and obese status as well as health problems caused by being overweight and obese. In addition, given that Asian mothers have a strong tendency to hold their traditional strict parenting practices (Julian et al. 1994), English fluent or bilingual mothers may play a protective role in reducing the risk of being overweight and obese among their children by strictly regulating their children's behaviors related to harmful weight gain through easy mother-child communication. Furthermore, these factors may also shed some light on why this study found more pronounced benefits on weight outcomes among children of English-dominant Asian mothers than those of bilingual Asian mothers.

In addition, consistent with as expected, this study also found lower BMI scores among children of bilingual Hispanic mothers compared with those of home-language Hispanic mothers. However, as found in prior research (Ariza et al. 2004; Sussner et al. 2008), maternal acculturation was not associated with probabilities of being overweight and obese among children of Hispanic mothers. Nevertheless, it is notable that lower BMI scores were found among children of bilingual Hispanic mothers, a group who may be acculturating and at the same time maintaining their traditional protective factors for children's health (e.g., traditional foods and dietary practices). This may be in line with prior research showing that Hispanic immigrant mothers tend to become aware of the association between unhealthy foods and weight gain when they are acculturating, and thus they tend to maintain their traditional foods and eating habits (Butte et al. 2007). In this sense, future research needs to look more deeply into diverse parental and family characteristics related to children's weight development within a sample of bilingual Hispanic immigrant families.

This study has several limitations. First, this study attempted to measure diverse acculturation patterns among recent Asian and Hispanic immigrants, but the proxy measure might not be fully culturally sensitive in capturing variations in the associations between maternal acculturation and children's weight development. Future work needs to use more culturally competent measures for young children in immigrant families. Second, due to sample size limitations, this study was not able to investigate variations by country of origin within each of the Asian and Hispanic groups. Given the growing request of recent research (e.g., Hernandez et al. 2013), future work needs to examine the heterogeneity within ethnic groups by using a dataset that includes a larger sample of children of immigrants.

Despite these limitations, the findings of this study contribute to the literature by demonstrating beneficial associations between maternal acculturation and child weight development at kindergarten entry among children of Asian and Hispanic immigrant mothers. Findings underscore that programs to promote the healthy development of young children in immigrant families may need to be tailored to different ethnic groups and levels of maternal acculturation. For instance, given that obesity among immigrants tends to spread through their social ties (Christakis and Fowler 2007; McDonald and Kennedy 2005), social workers may think of developing a community program that provides immigrant families embedded in social networks with services and education to improve parents' English 
language skills and knowledge about healthy early child development. In addition, the findings of this study also indicate that childhood obesity itself is in line with global trends (e.g., immigration), and thus suggest the need to consider this issue in a global context. For instance, it would be an important approach to situate childhood obesity in a global context through international organizations (e.g., the United Nations and the World Health Organization) in order to seek international cooperation to consider childhood obesity prevention as children's right to be protected against harmful influences on their healthy development (Waters et al. 2010).

\section{References}

Ariza, A. J., Chen, E. H., Binns, H. J., \& Christoffel, K. K. (2004). Risk factors for overweight in five- to six-year-old Hispanic-American children: a pilot study. Journal of Urban Health, 81(1), 150-161.

Au, L., Kwong, K., Chou, J. C., Tso, A., \& Wong, M. (2009). Prevalence of overweight and obesity in Chinese American children in New York City. Journal of Immigrant and Minority Health, 11(5), 337341.

Berry, J. W. (2005). Acculturation: living successfully in two cultures. International Journal of Intercultural Relations, 29(6), 697-712.

Butte, N. F., Cai, G., Cole, S. A., Wilson, T. A., Fisher, J. O., Zakeri, I. F., et al. (2007). Metabolic and behavioral predictors of weight gain in Hispanic children: the Viva la Familia Study. American Journal of Clinical Nutrition, 85(6), 1478-1485.

California Department of Health Care Services (n.d.). California pediatric nutrition surveillance system, 1994-2003 data. Avalable at http:// www.dhcs.ca.gov/services/chdp/Pages/PedNSS2003.aspx. Accessed 25 August 2014

Centers for Disease Control and Prevention (n.d.). 2000 CDC growth charts. Avalable at http://www.cdc.gov/nccdphp/dnpao/ growthcharts/index.htm. Accessed 25 August 2014

Chase-Lansdale, P. L., Valdovinos D'Angelo, A., \& Palacios, N. (2007). A multidisciplinary perspective on the development of young children in immigrant families. In J. E. Lansford, K. Deater-Deckard, \& M. H. Bornstein (Eds.), Immigrant families in contemporary society (pp. 137-156). New York, NY: Guilford.

Chen, J.-L. (2009). Household income, maternal acculturation, maternal education level and health behaviors of Chinese-American children and mothers. Journal of Immigration and Minority Health, 11(3), 198-204.

Chen, J-L., \& Kennedy, C. (2005). Factors associated with obesity in Chinese-American children. Pediatric Nursing, 31(2), 110-115

Cho, Y. Frisbie, P., Hummer, R. A., \& Rogers. R. G. (2004). Nativity, duration of residence, and the health of Hispanic adults in the United States. International Migration Review, 38(1), 184-211

Christakis, N. A., \& Fowler, J. H. (2007). The spread of obesity in a large social network over 32 years. New England Journal of Medicine, 357(4), 370-379.

Fuller, B., Bridges, M., Bein, E., Jang, H., Jung, S., Rabe-Hesketh, S., et al. (2009). The health and cognitive growth of Latino toddlers: at risk or immigrant paradox? Maternal and Child Health Journal, 13(6), 755-768.

Guendelman, S., Fernald, L. C., Neufeld, L. M., \& Fuentes-Afflick, E. (2010). Maternal perceptions of early childhood ideal body weight differ among Mexican-origin mothers residing in Mexico compared to California. Journal of the American Dietetic Association, 110(2), 222-229.

Hernandez, D. J. (2004). Demographic change and the life circumstances of immigrant families. The Future of Children, 14(2), 17-47.

Hernandez, M. G., Nguyen, J., Saetermoe, C. L., \& Suarez-Orozco, C. (2013). Frameworks and ethics for research with immigrants: new directions for child and adolescent development. San Francisco, CA: Jossey-Bass.

Julian, T. W., McKenry, P. C., \& McKelvey, M. W. (1994). Cultural variations in parenting: perceptions of Caucasian, AfricanAmerican, Hispanic, and Asian-American parents. Family Relations, 43(1), 30-37.

Lara, M., Gamboa, C., Kahramanian, M. I., Morales, L. S., \& Hayes Bautista, D. E. (2005). Acculturation and Latino health in the United States: a review of the literature and its sociopolitical context. Annual Review of Public Health, 26, 367-397.

McDonald, J. T., \& Kennedy, S. (2005). Is migration to Canada associated with unhealthy weight gain? Overweight and obesity among Canada's immigrants. Social Science \& Medicine, 61(12), 24692481.

Nader, P. R., O’Brien, M., Houts, R., Bradley, R., Belsky, J., Crosnoe, R., et al. (2006). Identifying risk for obesity in early childhood. Pediatrics, 118(3), e594-e601.

Ogden, C. L., Carroll, M. D., Curtin, L. R., Lamb, M. M., \& Flegal, K. M. (2010). Prevalence of high body mass index in US children and adolescents, 2007-2008. JAMA, 303(3), 242-249.

Rubin, D. B. (1987). Multiple imputation for nonresponse in surveys. New York: Wiley \& Sons

Salant, T., \& Lauderdale, D. S. (2003). Measuring culture: a critical review of acculturation and health in Asian immigrant populations. Social Science \& Medicine, 57(1), 71-90.

Shields, M. K., \& Behrman, R. E. (2004). Children of immigrant families: analysis and recommendations. The Future of Children, 14(2), 4-15.

Singh, G. K., Kogan, M. D., \& Yu, S. M. (2009). Disparities in obesity and overweight prevalence among US immigrant children and adolescents by generational status. Journal of Community Health, 34(4), 271-281.

Snow, K., Derecho, A., Wheeless, S., Lennon, J., Rosen, J., Rogers, J., et al. (2009). Early Childhood Longitudinal Study, Birth Cohort (ECLS-B), kindergarten 2006 and 2007 data file user's manual (2010-010). Washington, DC:National Center for Education Statistics, Institute of Education Sciences, U.S. Department of Education.

Sussner, K. M., Lindsay, A. C., \& Peterson, K. E. (2008). The influence of maternal acculturation on child body mass index at age 24 months. Journal of American Dietetic Association, 109(2), 218-225.

Van Hook, J., \& Baker, E. (2010). Big boys and little girls: gender, acculturation, and weight among young children of immigrants. Journal of Health and Social Behavior, 51(2), 200-214.

Van Hook, J., \& Balistreri, K. S. (2007). Immigrant generation, socioeconomic status, and economic development of countries of origin: a longitudinal study of body mass index among children. Social Science \& Medicine, 65(5), 976-989.

Waters, E., Swinburn, B., Seidell, J., \& Uauy, R. (Eds.) (2010). Preventing childhood obesity: Evidence, policy and practice. Hoboken, NJ:Wiley-Blackwell.

Whitaker, R. C., \& Orzol, S. M. (2006). Obesity among U.S. urban preschool children: relationships to race, ethnicity, and socioeconomic status. Archives of Pediatrics and Adolescent Medicine, 160(6), 578-584.

Wilson, D. K., \& Evans, A. E. (2003). Health promotion in children and adolescents: an integration of psychological and environmental approaches. In M. C. Roberts (Ed.), Handbook of pediatric psychology (pp. 69-83). New York, NY: Guilford Press. 